\title{
Study on Temperature Calibration System
}

\author{
X.J. Peng, K.T. Yang \\ Optoelectronic Science and Engineering \\ Huazhong University of Science and Technology \\ Wuhan,China
}

\begin{abstract}
In order to make video-monitoring camera output high quality video in a cabin with high temperature, it is very necessary for the temperature control circuit to drive heat sink and fan at the appropriate time. Moreover, quantitative analysis of the cooling effect is more important so as to get the thermal design guidelines. A temperature calibration system is developed to set accurate working point of the temperature control circuit and properly evaluate the cooling effect of the heat sink and fan. This system completely meets design requirements with high accuracy, ultra-low power, small size and secure wireless communication. It is proved by experiments in different operating environments that the measurement accuracy of this system is better than $0.03^{\circ} \mathrm{C}$. So it can work as a temperature calibrator instead of Fluke 753.It can also be used widely in other environmental parameter acquisition and calibration system.
\end{abstract}

Keywords-temperature calibration;quantitative analysis; high accuracy;filtering;ultra-low power;secure wireless communication

\section{INTRODUCTION}

To get high quality video is the most important function to video-monitoring camera. Many interferences, high temperature etc. have great negative effect on camera CCD [1]. It is hard for camera to get good video by itself. So some assistant measures must be taken to eliminate those negative influences on camera in order to get ideal video.

The video monitoring system used in the ship cabin is working in rough surroundings. Sometimes the temperature is up to 55

maximum length is $70 \mathrm{~cm}$. Heat sink, fan and temperature control circuit are installed at the bottom of the camera housing. Much experience show that the temperature control circuit often drives the heat sink and fanat thewrong time(earlier or later). What's worse, the cooling effect of the heat sink and fan is kept unknown. So it's necessary to develop a temperature calibration system, then it can be used to set accurate working point of the temperature control circuit and properly evaluate the cooling effect of the heat sink and fan to get the thermal design guideline.

This paper is organized as follows: In Section 2, we introduce design demands and our system hardware structure. Section III describes design of system hardware. In Section IV, design of system software is introduced. Section V describes experimental results in different environments. Finally, Section VI provides the conclusion for this paper.

\section{DESIGN DEMANDS AND SYSTEM HARDWARE STRUCTURE}

\section{A. Design Demands}

1. Measurement range of calibration system is to $0-55^{\circ} \mathrm{C}$ and accuracy is better than $0.1^{\circ} \mathrm{C}$.

2. This calibration system can set appropriate working point of temperature control circuit.

3. It should be lower $45^{\circ} \mathrm{C}$ inside even if the temperature is over $50^{\circ} \mathrm{C}$ outside the camera housing(the temperature is up to $\left.55^{\circ} \mathrm{C}\right)$.

4. This system can evaluate the cooling effect of heat sink and fan and get the thermal design guidelines.

5. It should be convenient to assembly and disassembly. Meanwhile, itfeaturesultra low power and minimum small size.

\section{B. System Structure and Working Principle}

The whole temperature calibration system is composed of 6 wireless measurement modules, a comprehensive temperature acquisition module and a PC. The system diagram is shown in figure 1.

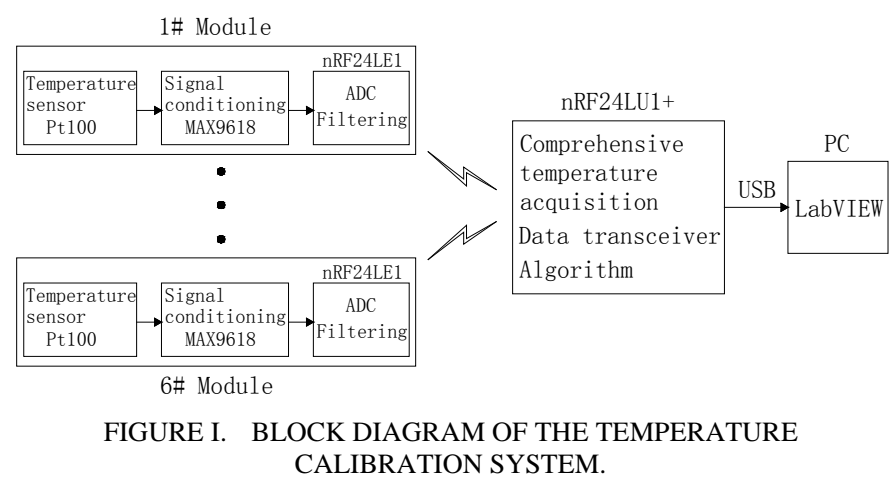

According to the design demands, 6 wireless temperature measurement modules are placed around the inside surface of the camera housing. Each module is used to measure the temperature of its own location. The location distribution is shown in figure 2.

Pt100 is used to detect temperature in the wireless temperature measurement module, the temperature data is transmitted to the comprehensive temperature acquisition module by RF (Radio Frequency) after signal conditioning and ADC (Analog-to-Digital Conversion). The comprehensive temperature acquisition module collects all the 6 temperature data and transmits them to PC via USB. The real-time average 
temperature of the camera housing is shown in LabVIEW program after some algorithm operations. The accurate working point of the temperature control circuit can be determined after the temperature comparison. What's more, the cooling effectcan be properly estimated and the thermal designing guideline can also be gotten.

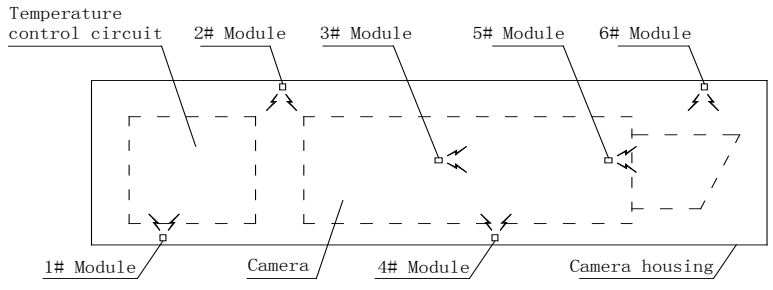

FIGURE II. LOCATION DISTRIBUTION OF THE WIRELESS TEMPERATURE MEASUREMENT MODULE.

\section{Selection Principle of Main ICs}

Ultra-low power and small size must be taken into account first. Considering themeasurement accuracy, measurement range and system working environment, the main ICs are selected as follows.

PTOD series Pt100 is used as temperature sensor in the temperature measurement module. Its error level is $Z(1 / 10$ DIN B), measurement range is $-50^{\circ} \mathrm{C}-200^{\circ} \mathrm{C}$, SMD footprint, size is only $1.6 \mathrm{~mm} \times 3.2 \mathrm{~mm} \times 0.9 \mathrm{~mm}$.

Signal conditional circuit is designed based on MAX9618[2]. MAX9618 is low-power, zero-drift, highefficiency operational amplifier available in a space-saving, $2 \mathrm{~mm}$ x 2mm SC70 package. It featuresultra-low 10pA input bias current and $10 \mu \mathrm{V}(\max )$ zero-drift input offset voltage over time and temperature.

nRF24LE1 [3] is used for ADC, software filtering, temperature calculation and RF transceiver. It is a low-cost, high-performance $2.4 \mathrm{GHz}$ transceiver with embedded 8051 microcontroller. Its transceiver features $6.8 \mathrm{~mA}$ current at $18 \mathrm{dBm}$ output power $3.0 \mu \mathrm{A}$ supply current at register retention and timers on mode. It is available in a compact $5 \mathrm{~mm} \times$ 5 mm 32-pin QFN.

The comprehensive temperature acquisition module is powered by PC and exchanges data with LabVIEW program. It is designed based on nRF24LU1+[4] with full-speed USB2.0 controller.

\section{DESIGN OF HARDWARE}

\section{A. Design of Wireless Temperature Measurement Module}

Nonlinear calibration is necessary before Pt100 is used because its resistance value is not in direct proportion to temperature. In order to get high measurement accuracy, bridge type temperature measurement circuits and microcontroller digital calibration are used here.

Signal conditional circuit is shown in figure 3. Bridge type measurement circuit is made up of R19, R20, VR1 and Pt100, in which R19 is equal to R20, VR1 is wire-wound rheostat. The bridge circuit outputs a $\mathrm{mV}$ level voltage differential signal if the thermal resistance value of Pt100 is not equal to VR1. A signal with expected value is gotten and sent to ADC after that $\mathrm{mV}$ level signal is differentially amplified by MAX9618[5] [6].

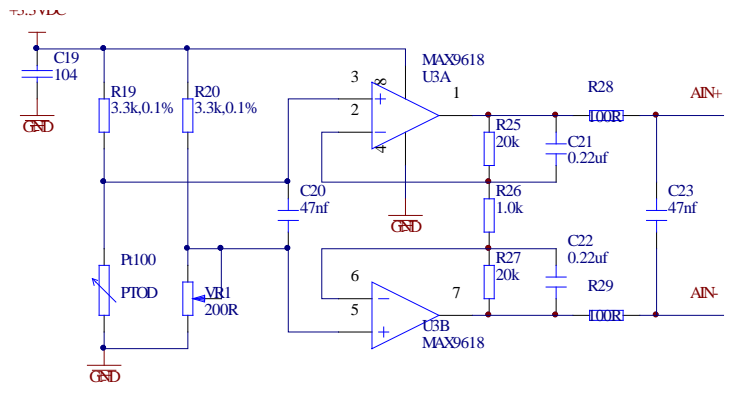

FIGURE III. SCHEMATIC DIAGRAM
CONDITIONING CIRCUIT.

The differential amplification factor of the signal conditional circuit is as follows:

$$
A=2 \times \frac{R_{25}}{R_{26}}+1
$$

The output signal is as follows:

$$
V_{\text {OUT }}=A_{I N+}-A_{I N-}=A \times V_{R E F} \times\left(\frac{R_{P t 100}}{R_{19}+R_{P t 100}}-\frac{R_{V R 1}}{R_{20}+R_{V R 1}}\right)
$$

In which the resistance value is subject to actual measurement.

B. Design of Comprehensive Temperature Acquisition Module

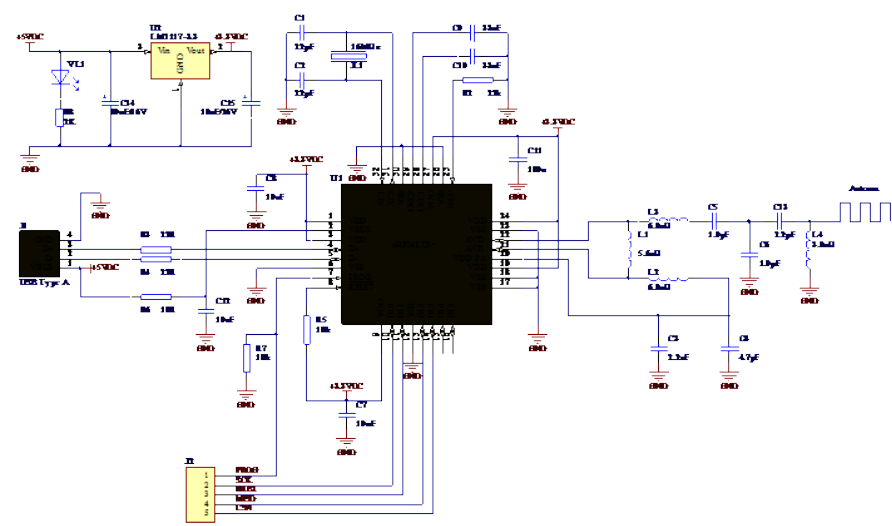

FIGURE IV

SCHEMATIC DIAGRAM OF NRF24LU1+.

The comprehensive temperature acquisition module is designed based on nRF24LU1+. It receives data from 6 temperature measurement module and transmits them to LabVIEW program in real time. The schematic diagram of nRF24LU1+ is shown in figure 4.

\section{DESIGN OF SOFTWARE}

\section{A. Software Filtering of ADC Sampling}

Experimental results show that weighted recursive average filtering is most effective here. Its principle is as follows: $\mathrm{N}$ samples in series make up of a queue. The newest sample is added and the first sample is deleted, First-In and First-Out 
rule works here. The length of the queue is always $\mathrm{N}$. Then a new filtering result generates after these $\mathrm{N}$ samples are weighted and taken an average [7].

Pt100 used here is a temperature sensor. So $\mathrm{N}$ is set to 4 in the program. ADC is performed every half a minute, so the samples of the queue are updated twice in a minute, that's to say, the first 2 samples are deleted and the newer 2 samples are added to the queue. Because the new samples responds to the current temperature, so the weights of these 4 samples $x 0$, $\mathrm{x} 1, \mathrm{x} 2, \mathrm{x} 3$ (from the first to the last) are 0.125, 0.125, 0.25 and 0.5 successively [8]. Therefore, the result of weighted recursive average filtering is as follows:

$$
\begin{gathered}
\operatorname{avg}=x_{0} \times w_{0}+x_{1} \times w_{1}+x_{2} \times w_{2}+x_{3} \times w_{3}(3) \\
\operatorname{avg}=x_{0} \times 0.125+x_{1} \times 0.125+x_{2} \times 0.25+x_{3} \times 0.5
\end{gathered}
$$

Because of the limited capacity of floating-point operations, nRF24LE1 performs shift operation in place of multiplication, namely,

$$
\operatorname{avg}=\left(x_{0} \square 3\right)+\left(x_{1} \square 3\right)+\left(x_{2} \square 2\right)+\left(x_{3} \square 1\right)_{(4)}
$$

\section{B. Design of Low Power}

The temperature measurement module is powered by button cell, so the program is coded following the guideline of low power. In order to reduce power, the module should be kept in power-down mode except of ADC and wireless data communication [9]. Main flow chart of the temperature measurement module is show in figure 5.

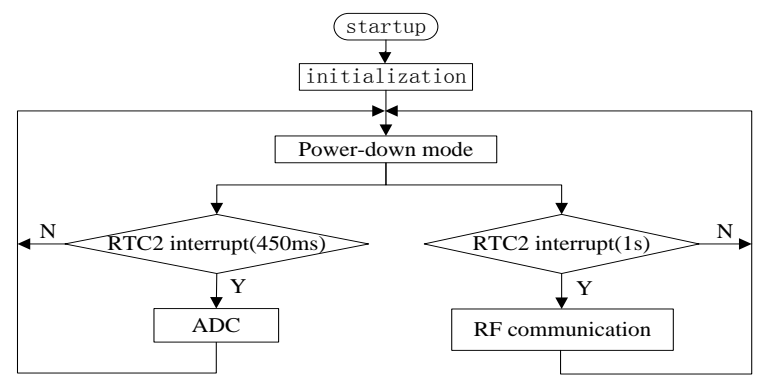

FIGURE V. MAIN FLOW CHART OF THE TEMPERATURE MEASUREMENT MODULE.

\section{Security Design of Wireless Data Communication}

The $2.4 \mathrm{GHz}$ devices are mainly the stable distribution frequency system such as W-LAN, and the frequency-hopping system such as Bluetooth.

Generally, nRF24LE1 should act on the following frequency-hopping rules:

1) There are sustaining frequency interference in the current channel;

2)Switch to the channel in which there is little probability of that disturbance source;

3) There is no need to change frequency if the interference is from another frequency-hopping system.
So the main interference that nRF24LE1 encounters is from W-LAN and conscious shared-frequency interference. The bandwidth of $\mathrm{W}$-LAN is $22 \mathrm{MHz}$. The following equation can be used to set the frequency-hopping table:

$$
f_{0}=i+j \times 22 \mathrm{i}=1,2,3 ; \mathrm{j}=1,2,3,4,5
$$

The following is a good example of frequency hopping table:uint8_tfreqSeq[9] $=\{0 \times 28,0 \times 49,0 \times 07,0 \times 19,0 \times 17,0 \times 2 f, 0 \times 1$ f,0x14,0x16\};

Each value in the frequency-hopping table above is chosen as a channel and changed quickly. So the interference from other $2.4 \mathrm{GHz}$ devices can be eliminated. Wireless data communication is quite secure in this way.

\section{EXPERIMENTS}

After LabVIEW program receives all the 6 temperature data, these data are assigned to different weights according to the location of the temperature measurement module. The nearer the temperature measurement module is away from $\mathrm{CCD}$, the bigger the weight is, and vice versa.

In this program, the weights assigned to the 6 temperature data are $0.05,0.1,0.15,0.2,0.3$ and 0.2 respectively. So the weighted and average result is as follows:

$$
\begin{aligned}
& \text { avg }=y_{0} \times w_{0}+y_{1} \times w_{1}+y_{2} \times w_{2}+y_{3} \times w_{3}+y_{4} \times w_{4}+y_{5} \times w_{5}(5) \\
& \text { avg }=x_{0} \times 0.05+x_{1} \times 0.1+x_{2} \times 0.15+x_{3} \times 0.2+x_{4} \times 0.3+x_{5} \times 0.2
\end{aligned}
$$

The camera housing, the 6 front-end temperature measurement modules included, is placed in electric thermostaticdrying oven.It lasts for 2 hours in $35^{\circ} \mathrm{C}, 42.0^{\circ} \mathrm{C}$, $45.0^{\circ} \mathrm{C}, 50.0^{\circ} \mathrm{C}$ and $55.0^{\circ} \mathrm{C}$ respectively and for an hour in $60{ }^{\circ} \mathrm{C}$. Documenting process calibrator Fluke 753 is used to calibrate temperature. The experiment results are shown in table 1.

Similarly, the camera housing, the 6 front-end temperature measurement modules included, is placed in electric thermostaticdrying oven. After internal and external temperature balance, the temperature control circuit begins to work in order to analyze quantitatively the cooling effects of heat sink and fan. Fluke 753 is also used here. 
TABLE I. EXPERIMENT RESULT.

\begin{tabular}{|c|c|c|c|c|c|c|c|}
\hline \multirow{2}{*}{$\begin{array}{c}\text { Electric } \\
\text { thermostaticdrying } \\
\text { oven }\left({ }^{\circ} \mathrm{C}\right)\end{array}$} & setting value & 35.0 & 42.0 & 45.0 & 50.0 & 55.0 & 60.0 \\
\hline & Fluke753 & 35.03 & 41.96 & 45.04 & 50.05 & 55.03 & 60.04 \\
\hline \multirow{3}{*}{$\begin{array}{c}\text { 1\# Temperature } \\
\text { measurement } \\
\text { module }\left({ }^{\circ} \mathrm{C}\right)\end{array}$} & Pt100 & 34.96 & 37.95 & 38.13 & 38.52 & 39.14 & 39.86 \\
\hline & Fluke753 & 35.01 & 37.98 & 38.17 & 38.57 & 39.19 & 39.90 \\
\hline & error & -0.05 & -0.03 & -0.04 & -0.05 & -0.05 & -0.04 \\
\hline \multirow{3}{*}{$\begin{array}{c}\text { 2\# Temperature } \\
\text { measurement } \\
\text { module }\left({ }^{\circ} \mathrm{C}\right)\end{array}$} & Pt100 & 34.95 & 38.24 & 38.59 & 39.15 & 39.74 & 41.68 \\
\hline & Fluke753 & 34.99 & 38.27 & 38.64 & 39.20 & 39.78 & 41.72 \\
\hline & error & -0.04 & -0.03 & -0.05 & -0.05 & -0.04 & -0.04 \\
\hline \multirow{3}{*}{$\begin{array}{c}\text { 3\# Temperature } \\
\text { measurement } \\
\text { module }\left({ }^{\circ} \mathrm{C}\right) \\
\end{array}$} & Pt100 & 35.06 & 38.54 & 39.18 & 39.81 & 40.75 & 42.36 \\
\hline & Fluke753 & 35.02 & 38.57 & 39.14 & 39.86 & 40.79 & 42.41 \\
\hline & error & 0.04 & -0.03 & 0.04 & -0.05 & -0.04 & -0.05 \\
\hline \multirow{3}{*}{$\begin{array}{c}\text { 4\# Temperature } \\
\text { measurement } \\
\text { module }\left({ }^{\circ} \mathrm{C}\right)\end{array}$} & Pt100 & 34.97 & 38.76 & 39.59 & 40.61 & 41.64 & 43.18 \\
\hline & Fluke753 & 35.03 & 38.80 & 39.55 & 40.65 & 41.69 & 43.23 \\
\hline & error & -0.06 & -0.04 & 0.04 & -0.04 & -0.05 & -0.05 \\
\hline \multirow{3}{*}{$\begin{array}{c}\text { 5\# Temperature } \\
\text { measurement } \\
\text { module }\left({ }^{\circ} \mathrm{C}\right)\end{array}$} & Pt100 & 35.08 & 38.92 & 40.14 & 41.06 & 42.14 & 43.67 \\
\hline & Fluke753 & 35.04 & 38.87 & 40.19 & 41.10 & 42.18 & 43.71 \\
\hline & error & 0.04 & 0.05 & -0.05 & -0.04 & -0.04 & -0.04 \\
\hline \multirow{3}{*}{$\begin{array}{c}\text { 6\# Temperature } \\
\text { measurement } \\
\text { module }\left({ }^{\circ} \mathrm{C}\right) \\
\end{array}$} & Pt100 & 35.12 & 39.35 & 40.46 & 41.63 & 42.85 & 44.10 \\
\hline & Fluke753 & 35.06 & 39.38 & 40.51 & 41.59 & 42.81 & 44.05 \\
\hline & error & 0.06 & -0.03 & -0.05 & \begin{tabular}{|l|}
0.04 \\
\end{tabular} & 0.04 & 0.05 \\
\hline \multirow{3}{*}{$\begin{array}{l}\text { average value in the } \\
\text { camera housing }\left({ }^{\circ} \mathrm{C}\right)\end{array}$} & LabVIEW & 35.04 & 38.80 & 39.69 & 40.58 & 41.58 & 43.07 \\
\hline & Fluke 753 & 35.03 & 38.81 & 39.71 & 40.61 & 41.61 & 43.10 \\
\hline & $\begin{array}{c}\text { average } \\
\text { error }\end{array}$ & 0.01 & -0.01 & -0.02 & -0.03 & -0.03 & -0.03 \\
\hline
\end{tabular}

TABLE II. EXPERIMENT RESULT 2.

\begin{tabular}{|c|c|c|c|c|c|c|c|}
\hline $\begin{array}{c}\text { Electric } \\
\text { thermostaticdryin } \\
\text { g oven }\left({ }^{\circ} \mathrm{C}\right)\end{array}$ & setting value & 40.0 & 44.0 & 48.0 & 52.0 & 56.0 & 60.0 \\
\cline { 2 - 8 } $\begin{array}{c}\text { average value in } \\
\text { the camera } \\
\text { housing }\left({ }^{\circ} \mathrm{C}\right)\end{array}$ & $\begin{array}{c}\text { initial(Fluke } \\
753)\end{array}$ & 40.04 & 43.98 & 47.95 & 52.01 & 56.06 & 60.02 \\
\cline { 2 - 8 } & $\begin{array}{c}\text { initial } \\
\text { LabVIEW) }\end{array}$ & 40.05 & 44.01 & 47.94 & 51.97 & 56.03 & 60.05 \\
\cline { 2 - 8 } & $\begin{array}{c}\text { final(Fluke } \\
753)\end{array}$ & 38.21 & 39.03 & 39.92 & 40.88 & 41.98 & 43.07 \\
\cline { 2 - 8 } & $\begin{array}{c}\text { final } \\
\text { (LabVIEW) }\end{array}$ & 38.22 & 39.05 & 39.94 & 40.91 & 41.95 & 43.10 \\
\hline $\begin{array}{c}\text { Time } \\
\text { consuming(s) }\end{array}$ & $\begin{array}{c}\text { from initial to } \\
\text { final }\end{array}$ & 42 & 79 & 132 & 184 & 231 & 286 \\
\hline $\begin{array}{c}\text { Status of } \\
\text { temperature } \\
\text { control circuit }\end{array}$ & over 38.20 ${ }^{\circ} \mathrm{C}$ & on & on & on & on & on & on \\
\cline { 2 - 8 } & under 37.80 ${ }^{\circ} \mathrm{C}$ & off & off & off & off & off & off \\
\hline
\end{tabular}

Table 1 shows that the measurement accuracy of the wireless temperature module is better than $0.06{ }^{\circ} \mathrm{C}$ and the measurement accuracy of this system is better than $0.03^{\circ} \mathrm{C}$. So this system can be used to calibrate the temperature control circuit instead of Fluke 753.

The heat sink and fan is at the bottom of camera housing, so the temperature is lower in the back and higher in the front. Temperature difference is up to $4.15{ }^{\circ} \mathrm{C}$ when the environmental temperature is $60^{\circ} \mathrm{C}$. Therefore, it's better to set working point of the temperature control circuit after the difference of environmental temperature, the temperature of module No.1 and No.6 and the average temperature is taken into account.

When the temperature is up to $60.04{ }^{\circ} \mathrm{C}$ in the electric thermostaticdrying oven, the temperature inside camera housing is only $43.10^{\circ} \mathrm{C}$. So the cooling effect of the heat sink and fan completely meets designing requirements.
Table 2 shows that it takes 42 seconds when temperature reduction is from $40.3{ }^{\circ} \mathrm{C}$ to $38.21^{\circ} \mathrm{C}$ and 286 seconds when temperature decreases from $60.04^{\circ} \mathrm{C}$ to $43.07^{\circ} \mathrm{C}$. Data shown in table 2 can be used as the thermal design guidelineof heat sink and fan.

In this way, the temperature control circuit can be set at a proper work point and drives the heat sink and fan when the environmental temperature is up to the limit. The camera always works in an appropriate temperature and outputs high quality video.

\section{CONCLUSION}

Experimental results in different operating environments show that this system completely meets design requirements and measurement accuracy is better than the design demands. It can work as a calibrator for the temperature control circuit used in video monitoring system. This systemfeatures high accuracy, ultra low power, small size and secure wireless communication. What's more, it's also a measurement system with good compatibility, expansibility and portability.It can be used in many environment parameters acquisition and calibration applications after some adaptive design.

\section{REFERENCES}

[1] PengXiaojun.Marine comprehensive data acquisition and video monitoring system based on LAN[J]. Ship engineering, 2012, 34(2): 117-120.

[2] MAX9617-MAX9620 Single/Dual SC70, Zero-Drift, High-Efficiency, 1.5MHz Op Amps with RRIO. 19-4753; Rev 6; 8/12.

[3] nRF24LE1 Ultra-low Power Wireless System On-Chip Solution, Production Specification v1.6.

[4] nRF24LU1+ Single Chip 2.4GHz Transceiver with USB Microcontroller and /Flash Memory, Production Specification v1.1.

[5] HE Pingan, PENG Xiaojun, WANG Weiping. EPC/CPC measurement system based on dual linear $\mathrm{CCD}[\mathrm{J}]$. Optoelectronics \& Laser technology, 2006, 17(5): 608-611.

[6] PrashanthHolenarsipur, Zero-Drift IA Takes The Strain Out Of Sensor Measurements, Electronic Design. February 28, 2008.

[7] PENG Xiaojun, FENG Xuechao. Study on a measurement system of ocean depth[J]. Piezoelectrics\&acoustooptics, 2013, 35(2),293-296.

[8] Kugelstadt, Thomas, "Auto-zero amplifiers ease the design of highprecision circuits," TI Analog Applications Journal (2005).

[9] Arjesh K, Sridharan K, Srinivasan K. The design and development of a web-based data acquisition system. IEEE Instruction and Measurement, 2002, 51(3): 427-432. 